\title{
Inclusion and Withdrawal Criteria for Growth Hormone (GH) Therapy in Children with Idiopathic GH Deficiency-Towards Following the Evidence but Still with Unresolved Problems
}

\author{
Joanna Smyczyńska
}

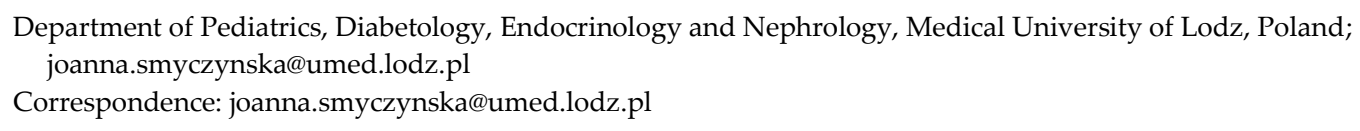

\begin{abstract}
According to current guidelines, growth hormone (GH) therapy is strongly recommended in children and adolescents with GH deficiency (GHD) in order to accelerate growth rate and attain normal adult height. The diagnosis of GHD requires demonstration of decreased GH secretion in stimulation tests, below the established threshold value. Currently, GHD in children is classified as secondary insulin-like growth factor-1 (IGF-1) deficiency. Most of children diagnosed with isolated GHD presents with normal GH secretion at the attainment of near-final height or even in mid-puberty. The most important clinical problems, related to the diagnosis of isolated GHD in children and to optimal duration of rhGH therapy include: arbitrary definition of subnormal GH peak in stimulation tests, disregarding factors influencing GH secretion, insufficient diagnostic accuracy and poor reproducibility of GH stimulation tests, discrepancies between spontaneous and stimulated GH secretion, clinical entity of neurosecretory dysfunction, discrepancies between IGF-1 concentrations and results of GH stimulation tests, significance of IGF-1 deficiency for the diagnosis of GHD, a need for validation IGF-1 reference ranges. Many of these issues have remained unresolved for 25 years or even longer. It seems that finding solutions to them should optimize diagnostics and therapy of children with short stature.
\end{abstract}

Keywords: short stature; growth hormone deficiency; insulin-like growth factor-1; growth hormone stimulation tests; neurosecretory dysfunction; final height; retesting

\section{Introduction}

According to current guidelines, growth hormone $(\mathrm{GH})$ therapy is strongly recommended in children and adolescents with GH deficiency (GHD) in order to accelerate growth rate and attain normal adult height [1]. The diagnosis of GHD is based on decreased GH secretion in stimulation tests, below the established threshold value. Along with the increase in availability of recombinant human $\mathrm{GH}(\mathrm{rhGH})$, less restrictive diagnostic criteria of GHD have been introduced, however without compelling evidence for any of the proposed cut-offs of GH peak in stimulation tests. From early 2000s, rhGH therapy is also approved in children born small for gestational age (SGA) with no catchup growth during first years of life. In United States (US), children with idiopathic short stature (ISS), who meet the established auxological criteria, may also be treated with $\mathrm{rhGH}$, conversely to European children with ISS who generally remain untreated. Besides, rhGH therapy with no requirement to confirm GHD is recommended in other clinical situations, e.g. in girls with Turner syndrome, children with Prader-Willi syndrome, in short children with chronic kidney disease and - in some countries - in children with skeletal dysplasia. Effectiveness of rhGH therapy with respect to growth response is the best in children with GHD, especially if the deficit of GH is severe and caused by genetic defects or organic abnormalities in the hypothalamic-pituitary region. 
In addition to promoting growth, $\mathrm{GH}$ also exerts numerous metabolic effects which are relevant throughout life. All the patients with persistent severe GHD, confirmed after completion of linear growth, should continue GH therapy in adulthood, even for a lifetime. It is recommended to re-evaluate GH secretion (e.g. to perform so-called retesting) in the majority of patients diagnosed in childhood with GHD, who completed growthpromoting therapy, apart from ones with deficiencies of at last 3 other pituitary hormones, with confirmed specific genetic mutations and/or major structural defects of hypothalamic-pituitary region [1]. The cut-off value of stimulated GH peak for the diagnosis of severe GHD in adults is much lower than that established for children. Therefore, only a minority of patients diagnosed with isolated, idiopathic GHD in childhood require continuation of rhGH therapy as adults, while a significant proportion of such patients exhibit completely normal GH secretion with respect to pediatric criteria after the therapy withdrawal. There is also the evidence that normal GH secretion may appear well before completion of linear growth, most likely already in mid-puberty [2].

The main peripheral mediator of most GH effects is insulin-like growth factor-1 (IGF-1). In current classifications, GHD in pediatric patients is considered synonymous with secondary IGF-1 deficiency (IGFD), however overlapping between IGF-1 levels in children with mild GHD and with ISS should be taken into account [3,4]. In the Guidelines from 2016 [1], measurement of IGF-1 concentration has been recommended for monitoring adherence to rhGH therapy and suggested for adjusting rhGH doses. However, this has been a conditional recommendation only, as the authors have concluded there were no published data sufficient for recommending IGF-1 based dosing of rhGH. Nevertheless, in the paper published in 2020, Wit et al. [5] have proposed measurement of IGF-1 concentration as an important part of screening in children with short stature. Assessment of short-term IGF-1 response to exogenous rhGH administration in so-called IGF-1 generation test was introduced for diagnosing GH insensitivity (GHI). Next, the same test has also been considered a marker of GH sensitivity [6,7]. Nevertheless, the significance of this test in diagnosing GHD and GHI has been questioned over the years by other authors [8-10]. The most important clinical problems, related to the diagnosis of isolated GHD in children and to the optimal duration of rhGH therapy in them, are listed in Table 1 and commented sequentially.

Table 1. Clinical problems related to the diagnosis of isolated GHD and to the optimal duration of rhGH therapy in children.

Problems related to direct assessment of GH secretion

1. Arbitrarily defined subnormal GH peak in stimulation tests.

2. Disregarding factors influencing GH secretion in interpreting the results of stimulation tests.

3. Insufficient diagnostic accuracy and poor reproducibility of GH stimulation tests.

4. Discrepancies between spontaneous and stimulated GH secretion.

5. Neurosecretory dysfunction of GH secretion as a clinical entity. Problems related to diagnosing GHD as secondary IGF-1 deficiency

1. Discrepancies between IGF-1 levels and the results of GH stimulation tests.

2. Significance of direct confirmation of secondary IGF-1 deficiency for the diagnosis of GHD.

3. Re-standardization of assays and the need for validation of IGF-1 reference ranges.

Problems related to the duration of rhGH therapy in children with idiopathic GHD

1. Discrepancies between IGF-1 levels and the results of GH stimulation tests.

2. Optimal time for rhGH therapy withdrawal and retesting of $\mathrm{GH}$ secretion. 


\section{Problems related to direct assessment of GH secretion}

The diagnosis of GHD seems certain in short children with hypothalamic-pituitary defects (congenital malformations, tumors and/or irradiation) and deficiencies of other anterior pituitary hormones, while it is still a challenge in children in whom the only clinical disorder is short stature [1].

The main diagnostic tools for assessment of GH secretion are stimulation tests with pharmacological agents. Due to the pulsatile pattern of GH release from the pituitary gland it is impossible to consider even very low $\mathrm{GH}$ concentration in single measurement as a reliable marker of GHD. Current guidelines indicate that the diagnosis of GHD requires to demonstrate decreased $\mathrm{GH}$ secretion in two $\mathrm{GH}$ provocative tests with different pharmacological stimuli, while waiver of such testing is possible only in selected patients with multiple pituitary hormone deficiency of a confirmed genetic or organic cause [1].

Some controversy about credibility of GH stimulation tests was presented by Rosenfeld et al. in 1995 [11]. The most important doubts concerned: the non-physiological nature of these tests, arbitrary definition of normal and subnormal GH response to stimulation, disregarding dependencies of GH secretion on the age and effect of sex steroids and unproved reproducibility of test results. The authors stated that GH stimulation tests could identify the patients with severe GHD but were of limited value to distinguish short normal children from those with partial GHD. Further reservations were related to the quality of assays used for measurement of GH concentration, as well as to the relatively high cost, inconvenience and potential risk of such diagnostic procedures. Unfortunately, most of these issues remain relevant nowadays, after more than a quarter of a century.

\subsection{Arbitrarily defined subnormal GH peak in stimulation tests}

The problem of arbitrary definition of normal and subnormal GH response to stimulation was described by Rosenfeld in 1995 [11]. Initially the cut-off value of GH peak in provocative tests was relatively low and increased gradually with increasing availability of $\mathrm{rhGH}$ from $5.0 \mathrm{ng} / \mathrm{ml}$ by $7.0 \mathrm{ng} / \mathrm{ml}$ to $10.0 \mathrm{ng} / \mathrm{ml}(\mu \mathrm{g} / \mathrm{l})$, however with no evidence to support any of these thresholds. The authors of the Consensus guidelines, published in 2000 [12] stated that GH peak below $10.0 \mu \mathrm{g} / \mathrm{l}$ had been traditionally used to confirm the diagnosis of GHD, however it should be verified (lowered) using next-generation tests based on monoclonal assays and rhGH reference preparations. In the same document the existence of a continuum of GH secretion and overlap of GH peaks in healthy children and those with GHD were emphasized. This issue was widely discussed by Savage et al. [4] who stated that there is a continuum of GH secretion and GH sensitivity, which range from severe GHD to severe GHI.

In a study of Bright et al. [13] on a large cohort of US prepubertal children, no difference in rhGH therapy effectiveness was observed between children with GH peaks between 5.0 and $10.0 \mu \mathrm{g} / \mathrm{l}$ and ones with GH peaks over $10.0 \mu \mathrm{g} / \mathrm{l}$. In other study, comparing auxological parameters (height SDS at diagnosis and predicted adult height), the results of GH stimulation tests and IGF-1 concentrations in 540 children with short stature, the only difference between the patients diagnosed with partial GHD (i.e. with GH peak in two stimulation tests between 5.0 and $10.0 \mu \mathrm{g} / \mathrm{l}$ ) and ones with ISS (i.e. with $\mathrm{GH}$ peak over $10.0 \mu \mathrm{g} / \mathrm{l})$ was the one between GH peaks in stimulation tests. Differently, children diagnosed with severe GHD (i.e. with GH peak below $5.0 \mu \mathrm{g} / \mathrm{l}$ ) had more pronounced deficit of height, lower IGF-1 levels and worse prediction of adult height [14].

While GH stimulation tests are quite accurate in the diagnosis of severe GHD, larger discrepancies appear in the patients with less severe disorders of GH secretion. In this situation, the diagnosis of severe GHD, based on GH peak after pharmacological stimulation below $5.0 \mu \mathrm{g} / \mathrm{l}$, is usually reliable, especially as deficiencies of other anterior pituitary hormones or abnormalities in the hypothalamic pituitary region are observed in a significant proportion of these patients. Conversely, the diagnosis of partial GHD, based on GH peak between 5.0 and $10.0 \mu \mathrm{g} / \mathrm{l}$ is burdened with a definitely higher risk of error [15]. The information that very low GH peak in stimulation tests is diagnostic for severe GHD, 
while the threshold for discriminating between children with partial GHD and ISS has not been established, is included in the recommendations of Grimberg et al. [1].

Although it seems obvious that different pharmacological agents should elicit different GH responses to stimulation, the diagnosis of GHD in children is still based on a single, arbitrarily established cut-off value for decreased GH secretion, which may vary by country but not by the type of test, except for the use of somatoliberin (GHRH). In the previously cited Consensus [12] using a limited number of provocative agents (clonidine, glucagon, insulin, arginine and L-dopa) in well standardized protocols was recommended for the assessment of GH secretion.

In 2014, Wagner et al. [16] made an attempt to validate GH concentrations measured with different immunoassays and to establish new cut-off limits for GH peak in stimulation tests. The authors have stated that these cut-offs should be different for particular assays, and on lower level than $10.0 \mu \mathrm{g} / \mathrm{l}$, for example $7.77 \mu \mathrm{g} / \mathrm{l}$ for IMMULITE 2000 (appropriate equations enabling converting these values for various assays have been listed in the cited manuscript). Otherwise, Murray et al. [17], have described the difficulties in establishing the optimal cut-off point for GH peak, noting that using auxological criteria was hampered, as findings in other disorders could be similar to that in GHD.

In current Guidelines of Grimberg et al. [1], related to GH therapy in children and adolescents, another important issue, concerning the lack of randomized controlled trials that correlated GH response to stimulation with the effect of rhGH on adult height has been stressed. Moreover, the authors have noted that the generally accepted threshold value diagnostic for GHD on the level of $10.0 \mu \mathrm{g} / \mathrm{l}$ was close to the median value of $\mathrm{GH}$ peak in stimulation tests documented in normally growing children. Thus, a strong recommendation has been issued against relying on $\mathrm{GH}$ provocative tests results as the sole diagnostic criterion of GHD.

\subsection{Disregarding factors influencing GH secretion in interpreting the results of stimulation tests}

It is generally accepted that GH stimulation tests require prior exclusion of hypothyroidism, as a condition that may impair GH secretion. Very important is also to recognize the influence of concomitant medications, particularly glucocorticoids and psychotropic drugs. Among the physiological factors, sex steroids and nutritional status have a significant impact on GH secretion [12].

One of first studies concerning dependency of GH secretion on age and pubertal stage, published in 1979 by Gourmelen et al. [18], documented the increase of GH release during puberty or after receiving sex hormones. Age dependency of GH secretion with particularly low values in early puberty, increasing gradually during mid-puberty up to late puberty, was confirmed almost 35 years ago by Mauras et al. [19] and few years later by Marin et al. [20]. Relatively low spontaneous GH secretion and GH response to pharmacological stimulation in prepubertal children is the cause of difficulties in proper differentiating between patients with true GHD and ones with constitutional delay of growth and puberty. In the previously cited study of Marin et al. [20], positive effects of exogenous estrogen administration on GH secretion, similar to those observed during puberty, were also reported, which was the rationale for introducing the estrogen priming in few days preceding GH stimulation tests. However, in the guidelines of GH Research Society from 2000 [12], a problem of low GH levels in stimulation tests during peripubertal period was stressed but with a constatation that there was no consensus on the use of sex steroids as priming before these tests.

In 2016, Grimberg et al. [1] have suggested sex steroid priming prior to GH stimulation tests in selected groups of prepubertal children (boys over 11 and girls over 10 years old) with a prognosis of adult height within normal range. This procedure has been aimed at avoiding unnecessary rhGH therapy in case of constitutional delay of growth and puberty, misdiagnosed as GHD. However, this has only been a conditional recommendation.

The same year, Murray et al. [17] have highlighted the existence of different approaches to priming and different schemes of carrying it out. The main and so far valid 
doubts have concerned the question of whether priming reduced the rate of false positive results of GH stimulation tests or it deprived children with transient prepubertal GHD from treatment. In that review, only one study of Gonc et al. [21] has been cited, which confirmed that untreated boys with subnormal GH peak in unprimed GH stimulation tests but normal GH response after sex steroid priming had no impaired final height.

Next year, Radetti et al. [22] have proposed using pegvisomant as a new type of priming enhancing GH secretion, enabling to decrease the rate of false positive results of $\mathrm{GH}$ stimulation tests in children. As the study has been performed on a relatively small group of patients, its promising results seem to require further validation.

Obesity and overweight have a well-documented negative influence on GH secretion. Stanley et al. [23] reported an inverse correlation between GH peak in stimulation tests (expressed as natural log) and body mass index (BMI) SD score (SDS). This association remained significant even after controlling for age, sex and pubertal status, and was confirmed for a wide range of BMI values, not only for obesity. Higher BMI values increased the likelihood of a diagnosis of GHD for different cut-off points for GH peak in stimulation tests $(5.0,7.0$ and $10.0 \mu \mathrm{g} / \mathrm{l})$. The authors draw a conclusion that BMI should be regarded while interpreting the results of GH stimulation tests, as higher values of BMI SDS - even within normal range - could be associated with overdiagnosing GHD.

Another approach to the same issue has been proposed by Barrett et al. [24], who compared short prepubertal children with GH peaks in stimulation tests below or over $10.0 \mu \mathrm{g} / \mathrm{l}$, who were either overweight/obese or normal-weight. The main findings in this study were: significantly lower GH peaks in overweight/obese children than in normalweight ones, despite similar IGF-1 levels and growth rates in both groups, and the much higher likelihood to obtain subnormal GH peak in case of overweight/obesity. In Korean study on short children with short stature, a negative impact of BMI on GH peak in stimulation tests has also been confirmed, especially for the test with clonidine; moreover, among children with GHD, better outcomes of rhGH therapy were observed in those with obesity than in non-obese ones [25]. Lenartsson et al. [26] have reported similar clinical characteristics of children with GH peaks below or over $7.0 \mu \mathrm{g} / \mathrm{l}$, except for body weight and BMI SDS.

Recently, a systematic review and meta-analysis, concerning the impact of BMI on the results of GH stimulation tests in children and adolescents has been published [27]. As a summary of the meta-analysis, the authors proposed different cut-offs for GH peak in stimulation tests for children with normal weight, overweight and obesity.

Despite the well documented fact that GH responses in stimulation tests are blunted in overweight and obese patients, this phenomenon is taken into account when interpreting these tests in adults but still not in children [1].

\subsection{Insufficient diagnostic accuracy and poor reproducibility of GH stimulation tests}

There is no doubt that no single GH stimulation test has sufficient specificity to confirm isolated GHD. Performing at least two tests has been suggested as a way to increase their sensitivity and specificity when interpreted together, however with rather a weak evidence justifying such a procedure [11,15]. The principle of performing two different stimulation tests results from the relatively high rate of false positive results in a single test, i.e. decreased GH peak in an actually GH-sufficient child, that may be caused e.g. by a spontaneous GH pulse occurring shortly before the test [28].

In 1995, Rosenfeld et al. [11] stated that performing GH provocative tests sequentially or with combined stimuli might be time-saving and increasing cost-effectiveness but there was no evidence that such approach could increase sensitivity or specificity of these tests. It seems reasonable that for independent assessment of GH secretion in two stimulation tests, these tests should be performed in separate days to allow time to restore GH pituitary reserve, while the result of the second from the two consecutive tests may be affected by down-regulation of the hypothalamic-pituitary axis [29]. If it is known that GH peak in a stimulation test, performed shortly after spontaneous GH surge may be blunted [26], 
the more it applies to the result of the second of two stimulation tests performed consecutively on the same day. Webb and Dattani [15] suggested taking special care in interpreting the second of the successive tests and applying a different cut-off criteria for each test. Although in this context it may seem somewhat puzzling, according to current Guidelines [1] there is still no evidence against performing two GH provocative tests sequentially in one day. The authors of these recommendations, however, have paid attention to a possibility that stimulation tests with combined agents might yield different results from the same tests performed separately.

Problems with poor reproducibility of GH stimulation tests in poorly growing children, reported in 1990 by Zadik et al. [30] and 5 years later by Hinz [31], remain unresolved for over 30 years. In fact, the high incidence of false positive results of GH stimulation tests has been the main reason for performing two stimulation tests in order to avoid overdiagnosing GHD and thereafter overtreatment of non GH-deficient children [17].

Moreover, it should be borne in mind that obtaining a false positive result (e.g. decreased GH peak in a GH-sufficient child) in one test does not guarantee that the result of the second test is true. In the analysis using the theory of probability, including the results of two GH stimulation tests with different pharmacological agents, performed consecutively in a group of 780 children with short stature and excluded other disorders of pituitary gland, the frequency of falsely positive results of both tests was estimated at $19.2 \%$, while the total incidence of GHD was $40.8 \%$ [32].

Twenty years ago, Loche et al. [33] proved the hypothesis that in prepubertal children with normal magnetic resonance (MR) of the hypothalamic-pituitary region normalization of GH response to stimulation might occur much earlier than at the attainment of final height, even before entering puberty and within a few months from previous assessment. Thus the authors suggested that patients with subnormal GH response in stimulation tests despite normal MR required follow-up and reevaluation before the diagnosis of GHD was established. Moreover, they noted that the observed early normalization of the results of $\mathrm{GH}$ stimulation tests might be related either to real improvement of $\mathrm{GH}$ secretion or to the poor reproducibility of GH stimulation tests, resulting in a high incidence of falsely subnormal results of these tests in normal subjects. In that study, serum IGF-1 concentrations did not correlate with the results of GH stimulation tests both at first evaluation and during retesting.

In order to explain the described phenomenon, our research group [34] decided to repeat GH stimulation tests and IGF-1 measurements in a group of patients with a wide range of GH responses to stimulation, no other hormonal deficiencies and no organic abnormalities in hypothalamic-pituitary region. We observed not only normalization of previously decreased GH secretion but also the opposite situation, i.e. lowering the previously normal GH secretion. Somewhat surprisingly, IGF-1 concentrations in both assessments correlated with each other much stronger than GH peaks in stimulation tests repeated in the same two time points. These findings pointed at the poor reproducibility of $\mathrm{GH}$ stimulation tests rather than the true normalization (or deterioration) of GH secretion.

\subsection{Discrepancies between spontaneous and stimulated GH secretion}

Despite the fact that - theoretically - 24-hour profile of GH secretion should be more reliable procedure in diagnosing GHD than GH stimulation tests, there is also a strong recommendation against the assessment of spontaneous $\mathrm{GH}$ secretion in diagnosing GHD, due to scarcity of data on advantage of such procedure, overlap between the results obtained during frequent GH sampling in children with GHD (diagnosed according to standard criteria) and healthy controls, as well as the poor reproducibility of spontaneous GH secretion [1,35]. Thus the results of GH stimulation tests are generally considered more reliable in diagnosing GHD than assessment of nocturnal or 24-hour profile of GH secretion [1].

Pediatric endocrinologists in Poland have a relatively large experience in assessment of GH secretion after falling asleep. Obara-Moszyńska et al. [36] showed that sleep was a 
stronger stimulus for GH secretion than commonly used pharmacological agents (insulin, clonidine, L-dopa, glucagon) in prepubertal children. Presenting the results of statistical analysis concerning the accuracy of standard pharmacological stimulation tests, the authors clearly declared that "it was assumed that pituitary insufficiency might be diagnosed by GH levels below $20 \mu \mathrm{IU} / 1(10.0 \mu \mathrm{g} / \mathrm{l})$ in the GH surge test after sleep onset", drawing from these results a far-reaching (albeit coinciding with the previously adopted assumption) conclusion that the test of GH secretion after falling asleep might be a screening procedure in diagnosing GHD. Unfortunately, the cited study only compared the results of different tests of GH secretion, with no follow-up including the effectiveness of GH therapy in the patients diagnosed with GHD according to different criteria, as well as observation of spontaneous growth of untreated subjects labelled consistently with these criteria as GH-sufficient. It seems that such an approach may raise some reservations regarding the adopted methodology of the study, especially in relation to the introduction of a nationwide screening test, which allows in practice to waive further diagnostics towards GHD in a short child. Anyway, in Poland 3-hour test of spontaneous GH secretion after falling asleep (5 time points, every 30 minutes from 60 to 180 minute of sleep) has gained a range of an obligatory screening procedure for many years.

In order to ensure that the test of GH secretion after falling asleep meets the requirements for screening tests (mostly 95\% sensitivity), a different approach has been used the accuracy of the result of nocturnal test of GH secretion has been assessed with respect to the results of two pharmacological GH stimulation tests interpreted together according to current rules (considered a reference procedure. In a group of one thousand children with short stature, only $70.4 \%$ sensitivity and $61.2 \%$ specificity of the nocturnal test has been proved using the same cut-off value of GH peak $(10.0 \mu \mathrm{g} / \mathrm{l})$ for all tests, while the $95 \%$ sensitivity of nocturnal test required increasing the cut-off $\mathrm{GH}$ peak up to $19.0 \mu \mathrm{g} / \mathrm{l}$, which, however, has been associated with a reduction of its specificity to just below $25 \%$, making the test under validation rather useless as a screening procedure [37].

In the context of these considerations, of particular importance seems to be the report by Rose et al. from the late 1980s [38], who stated that 24-hour profile of spontaneous GH secretion had better reproducibility than GH stimulation tests, however it could not identify as much as $57 \%$ of children diagnosed with GHD by stimulation tests.

Similarly, in a very recent study, Lennartsson et al. [26] have reported significant differences between spontaneous and stimulated GH peaks, with higher frequencies of divergent results for higher cut-offs applied. In this study, a problem of refractoriness, described as decreased GH peaks in stimulation tests started within short time after a spontaneous GH peak, has also been raised. The duration of such a refractory period has been estimated to be approximately 2 hours. This phenomenon may partly explain both divergent results and poor reproducibility of the tests assessing spontaneous and stimulated GH secretion. The authors have suggested that evaluation of spontaneous GH secretion just before stimulation tests could help to avoid overdiagnosing GHD.

\subsection{Neurosecretory dysfunction of GH secretion as a clinical entity}

In the Consensus Guidelines form 2000 [12], evaluation of spontaneous GH secretion was proposed for patients with normal GH peak after pharmacological stimulation but decreased IGF-1 level, suspected for neurosecretory dysfunction (NSD) of GH secretion, however with the comment that this diagnosis was uncommon, except for the patients with a history of cranial irradiation. The diagnosis of NSD is included in ESPE Classification of Paediatric Endocrine Disorders [3], but with the comment that spontaneous GH secretion is highly variable and may be very low in normally growing children. It seems worth mentioning that the effectiveness of GH therapy in children with NSD was documented in 1984 for the small group of patients in the study of Spiliotis et al. [39]. In 1995, Hintz [31] proposed to diagnose NSD in extremely short children (height below or equal to 1 st centile for age) with slow growth rate, delayed bone age and normal GH peak (over or equal to $10.0 \mathrm{ng} / \mathrm{ml}$ ) on provocative testing but low 12- or 24-hour GH secretory pattern, 
however pointing at the lack of reproducibility of both GH provocative testing and 24hour GH sampling. Strong support for the idea of assessing spontaneous GH secretion in diagnosing GHD was a study of Radetti et al. from 2003 [40], which indicated that rhGH administration in children with short stature but normal spontaneous GH secretion was not associated with a clinically significant increase in height SD score, irrespectively from normal or decreased GH peak in stimulation tests. The authors of Guidelines published in 2016 [1], have stated that it was the only study assessing the effectiveness of rhGH therapy in children with NSD with respect to adult height.

Against, also in 2003, Rogol et al. [41] published a study on large group of prepubertal children, showing that the differences between spontaneous GH secretion between children with idiopathic GHD and ISS were lower than those between GH peaks after stimulation, however with more disordered patterns of spontaneous GH secretion in ISS. Additionally there was no difference in IGF-1 levels between the groups diagnosed with GHD and ISS. Last but not the least was the observation that there was no significant difference between the increase of height SDS between the groups of children with idiopathic GHD and ISS, wherein height SDS increase correlated inversely with variables related to spontaneous GH secretion and with IGF-1 concentrations only in the subgroup of children with severe GHD but not in ones with partial GHD or ISS. The authors concluded that in children with severe deficit of height diagnosed with ISS, the problem might be related to less coordinated and thus less effective spontaneous GH secretion, however such diagnostics seemed unnecessary as rhGH therapy effectiveness was similar in children with ISS and mild GHD. Unfortunately, in Europe, children with even very severe short stature and normal results of GH stimulation tests are not qualified to rhGH therapy, until they are born SGA or have other clinical conditions which entitle to treatment regardless of GH secretion.

Taking into account the scarcity of data supporting GH therapy in patients with NSD, as well as the difficulties in establishing normative data for spontaneous GH secretion (overnight GH secretory patterns compatible with diagnosis of GHD in normally growing children, overlapping of spontaneous GH secretion between normally growing children and ones diagnosed with GHD, poor reproducibility of serial GH sampling under identical conditions on two separate occasions), the authors of cited Guidelines [1] have strongly recommended against the measurement of spontaneous GH secretion in diagnosing GHD.

Recently NSD has been reconsidered as a disease associated with good GH sensitivity but decreased GH secretion [17,42]. Wit et al. [35] have summarized the results of the research on physiological GH secretion in children, pointing to its relationships not only with height SDS and height velocity but also with nutritional status and pubertal stage, which presented to be the major determinant spontaneous GH secretion. The authors have also paid attention to a relative scarcity of studies comparing 24-hour GH secretion in children with short stature and healthy controls. Nevertheless, it has recently been suggested by Lennartsson et al. [26] that the assessment of 12- or 24-hour profile of GH secretion may reduce qualification to rhGH therapy children with false positive results of $\mathrm{GH}$ stimulation tests by about $20 \%$, however the data concerning final height of treated and untreated children have not been available, which the authors themselves considered a limitation of their study. On the other hand, children with decreased spontaneous GH secretion (i.e. ones with NSD) may benefit during rhGH therapy despite normal results of GH stimulation tests.

Wit et al. [35] described various strategies for dealing with such patients: a trial of rhGH therapy (permitted in Sweden and US), abstaining from any treatment (as currently e.g. in Poland) or very interesting option of performing IGF-1 generation test and starting rhGH therapy only if IGF-1 response is good (permitted in Netherlands). Binder et al. [43] in a very recent study have shown similar effectiveness of rhGH therapy with respect to the attained adult height in children with NSD and with idiopathic GHD. The results of this study correspond to the previously cited report of Rogol et al. [41]. 


\section{Problems related to diagnosing GHD as secondary IGF-1 deficiency}

Since GHD has been defined as secondary IGF-1 deficiency, assessment of IGF-1 secretion has become a mandatory component of GHD diagnostics [3]. Other possible causes of low IGF-1, such as malabsorption syndromes, malnutrition, liver diseases, renal failure or other severe chronic diseases, should be considered in diagnostic process. Similarly to physiological GH release, also IGF-1 secretion is age-dependent, increasing particularly during puberty, however serum concentration of IGF-1 is much more stable.

Recently, Wit et al. [5] have proposed assessment of IGF-1 concentration as a part of laboratory screening in children with growth failure with different cut-offs dependent on clinical pre-test likelihood of GHD. The authors have stressed that the results of IGF-1 measurements should be expressed as SDS with respect to appropriate reference data for age and sex of the patients, and adjusted for their pubertal stage and nutritional status. It has also been proposed that lower cut-offs should be applied for the patients with low and very low clinical likelihood of GHD, while higher for those in whom GH stimulation tests might be indicated regardless of IGF-1 concentration (e.g. for children after irradiation).

\subsection{Discrepancies between IGF-1 levels and the results of GH stimulation tests}

The lack of good correlation between GH secretory status and serum IGF-1 concentrations was described by Rosenfeld et al. [11], who presented the results of previous research on this issue. Interestingly, in one of studies cited in this article, published by Blum et al. [44], a significant correlation $(r=0.78)$ was reported between calculated 24-hour GH secretion rates and IGF-1 concentrations in healthy children.

It was quite clearly stated in the Consensus of GH Research Society [12] that IGF-1 concentrations below the cut-off on the level of $-2.0 \mathrm{SD}$ for age and sex were strongly suggestive for GHD after exclusion of other causes of decreased IGF-1 secretion, nevertheless, normal IGF-1 values could also be found in children with GHD. The same statement is currently valid for adults, despite the fact that in children GHD has been classified as secondary IGF-1 deficiency [3,45]. Murray et al. [17] have stressed the difficulties related to overlap of IGF-1 concentrations in GH-deficient and healthy children, especially in younger age groups, decreased IGF-1 levels in children with malnutrition, hypothyroidism, renal failure, diabetes and other chronic diseases, as well as an increase of IGF- 1 secretion during puberty. From the clinical point of view, very important is the suggestion that in children with delayed puberty, IGF-1 concentrations should be interpreted in relation to their bone age and pubertal stage.

The authors of many studies have evaluated the diagnostic value of IGF-1 assessment in children with respect to $\mathrm{GH}$ peak test stimulation tests, taken as a reference procedure. Recently, Ibba et al. [46] have established the best cut-off value of IGF-1 for the diagnosis of GHD on the level -1.5 SDS, however simultaneously documenting the poor accuracy of IGF-1 measurement in discriminating patients with confirmed or excluded GHD (that is with GH peak in stimulation tests below or over $7.0 \mu \mathrm{g} / \mathrm{l}$, respectively). Also, in a very recent study of Iwayama et al. [47], a poor diagnostic accuracy of IGF-1 measurement as a screening test for GHD has been found in Japanese children with short stature or decreased growth velocity if $\mathrm{GH}$ peak in stimulation tests has been considered a reference test. Very similar were earlier observations concerning assessment of IGF-1 concentrations as a screening procedure in diagnosing GHD in Polish children [48]. However, in other study, the same research group [34] reported the stability of IGF-1 concentrations despite divergent results of $\mathrm{GH}$ stimulation tests repeated in the same patients, which raised doubts as to whether the results of GH stimulation tests were actually more reliable than measurements of IGF-1 concentration.

A possible solution to these problems may be introduction of new diagnostic tests, such as assessment of GH secretion in stimulation tests after priming with pegvisomant, which results have correlated with IGF-1 levels [22]. Unfortunately, this study has been performed on a relatively small group of children and thus requires further validation. 
In this context, very interesting seem to be the data presented by Meazza et al. [49], who have measured serum levels of $\alpha$-klotho - a transmembrane protein which circulating soluble form (s-klotho) concentration reflects GH secretory status. They authors have reported no significant difference in both IGF-1 and s-klotho between the groups of short children diagnosed with GHD and ISS on the basis of pegvisomant-primed insulin-tolerance test, however with a good correlation between s-klotho and IGF-1 in both groups. They have concluded that s-klotho could not be considered a reliable marker of GH secretion in children, as it reflected IGF-1 levels but not GH peaks. However, it seems that opposite interpretation of these results is justified, pointing at the agreement of different markers of GH secretory status with each other, with the exception of GH stimulation tests.

Regarding the evident discrepancies between the results of $\mathrm{GH}$ stimulation tests and IGF-1 concentrations, there seems to be no strong evidence to show that subnormal GH peak is more reliable for the diagnosis of GHD than decreased IGF-1 level. Otherwise, assuming that IGF-1 concentrations as the reference test, the accuracy of GH stimulation tests would be poor. Moreover, taking into account the lack of correlation between the results of different GH stimulation tests or even the same test repeated in the same patient in a short time interval, it may actually be difficult to find any test that correlates with the results of other tests that do not correlate with each other.

\subsection{Importance of direct confirmation of secondary IGF-1 deficiency in the diagnosis of GHD}

Since it has become possible to use recombined human IGF-1 (rhIGF-1) in extremely short children diagnosed with GHI, the problem of proper differentiation between primary and secondary IGFD (i.e. between GHI and GHD) has become particularly important. Considering all the caveats about GH stimulation test, including their arbitrary cut-off points, insufficient sensitivity and specificity, poor reproducibility and discrepancy with spontaneous GH secretion, it would seem prudent to directly assess IGF-1 response to GH administration. For this purpose, IGF-1 generation test could be used as a diagnostic tool. The test based on measurements of IGF-1 concentrations before and after short-term rhGH administration was initially accepted for diagnosing GHI, with the lack of IGF-1 increase diagnostic for this condition [50]. The use of IGF-1 generation test (in a 10-days variant) for prediction of growth response to human GH was proposed 40 years ago by Rudman et al. [51], who confirmed the relationship between somatomedin C (former name of IGF-1) increase during the test and growth response to treatment in a small group of children with normal-variant short stature. Unfortunately, the poor reproducibility of IGF-1 generation test was also reported, that became be a significant limitation of its clinical utility [52].

Rosenfeld at al. [11] presented a statement that IGF-1 concentrations might reflect functional $\mathrm{GH}$ secretion better than direct assessment of $\mathrm{GH}$ peaks in stimulation tests. Documenting impaired GH secretion in the patients with IGFD had significant value for exclusion GHI a cause of growth retardation in such patients as. The authors directly questioned GH stimulation tests as a "gold standard" in diagnosing GHD, concluding that available methods for assessment of GH secretion were neither convenient nor reliable. As, in turn, IGF-1 concentrations might be influenced by factors other than GH secretion, the need for clinical evaluation of children with growth retardation, including serial measurements of height and calculating height velocity, was emphasized in the cited paper. At the same time the authors cautioned against expansion of the diagnosis of GHD and increasing market for commercial rhGH.

Currently in different countries, children with extremely short stature, severe IGFD and normal results of GH stimulation tests may be diagnosed with primary IGFD and treated with rhIGF-1, with no necessity of confirming GHI by performing IGF-1 generation test even in if a causative genetic diagnosis has not been established. In Poland, documenting lacking or insufficient increase of IGF-1 in generation test remains an obligatory procedure before qualifying children to the therapy with rhIGF-1. Thus, children with 
confirmed GHI may be treated with rhIGF-1, while those with good increase of IGF-1 concentration during short-generation test are still diagnosed with ISS and should remain untreated if they are born appropriate for gestational age (AGA). In fact, in Poland SGA but not AGA children with normal GH secretion may be qualified to rhGH therapy, even if they fulfill the criteria suggesting GHI, with no requirement to rule out this condition. This situation results from the applicable regulations but is difficult to be rationally explained to the patients and their parents.

Our study group has assumed that children with confirmed IGF-1 response to rhGH in generation test had secondary IGFD related to the disorders of GH secretion not matching the standard criteria for the diagnosis of GHD (or to GH bioinactivity) but remained GH-sensitive. So, we have compared effectiveness of rhGH therapy in such patients (IGFD group) divided into SGA and AGA subgroups, and in children with isolated GHD, observed up to the attainment of niear-FH. The increase of height SDS has been similar in the patients with IGFD and with GHD. Interestingly, the therapy has turned out to be the most effective in IGFD-AGA subgroup (i.e. in the only subgroup which do not fulfill current criteria of qualifying to rhGH rherapy), while the less effective in IGFD-SGA, however the differences between all 3 groups presented to be insignificant [53]. Our observations have supported the possibility of growth response to rhGH therapy in children who in some other countries could be diagnosed with GHI and treated only with rhIGF1. It should be stressed here that Grimberg et al. [1] in recent Guidelines, concerning GH and IGF-1 treatment in children and adolescents, have strongly recommended a trial of rhGH therapy before initiation IGF-1 administration in children with unexplained IGFD. The authors have also stated that rhGH, if effective, should be preferable to IGF-1 even in the patients with a partial GHI, due to some reasons, including IGF-1 independent effects of GH on growth plates, twice less number of injections, no risk of hypoglycemia and simultaneous increase of IGFBP-3 with IGF-1, which is considered favorable regarding the risk of cancers.

Moreover, it has been shown that significant increase of IGF-1/IGBBP-3 molar ratio predicted good response to rhGH therapy in children with IGFD but normal results of GH stimulation tests [54]. The usefulness of this parameter for monitoring and optimizing rhGH therapy in children with GHD has also been demonstrated [55]. Recently, IGF1/IGFBP-3 molar ratio has been considered an useful parameter for assessing safety of rhGH therapy [56].

\subsection{Re-standardization of assays and the need for validation of IGF-1 reference ranges}

Interpretation of IGF-1 concentrations requires appropriate age-and sex-related reference data, that should be established for particular assays and - optimally for particular laboratories. The latter approach may be difficult in practice as it requires obtaining blood samples from a large cohort of healthy children of different ages in each center. To overcome this problem, central measurement of IGF-1 levels has been proposed, however such a solution entails the necessity to properly secure the samples for transport, generates additional costs and delays getting results of the tests. In practice, it is possible to use the reference data published for the laboratory method used in a given center.

In our laboratory IGF-1 and IGFBP-3 concentrations were measured with kits provided by IMMULITE and the reference data provided by Elmlinger et al. [57] were used, which were constructed with appropriate methodology, taking into account the fact that due to the log-normal distribution of IGF-1 concentrations, calculation of IGF-1 SDS requires using log-transformed values [58].

Unfortunately, in 2016 new re-standardized assays for IGF-1 measurement have been introduced on IMMULITE systems. Despite the fact that the results obtained with previously used and re-standardized assays have correlated very well and a linear equation has been proposed to re-calculate values obtained with "old" and "new" assays, the problem has appeared with the provided new reference data, not taking into account the lognormal IGF-1 distribution and introducing several-year age ranges for children, instead 
of annual ones. Centile charts drawn with the use of these Pediatric Reference Ranges, provided in Table 5 of the cited Bulletin [59] illustrate problems with their use in clinical practice (Figure 1).

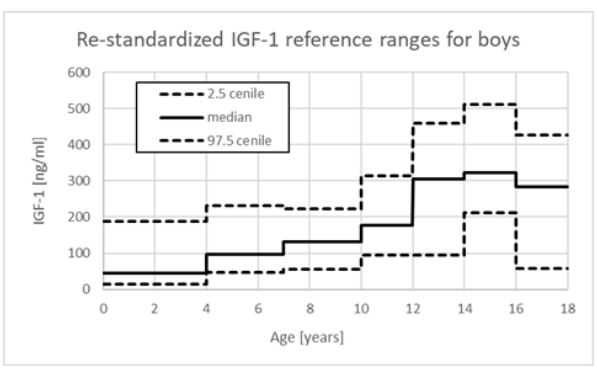

(a)

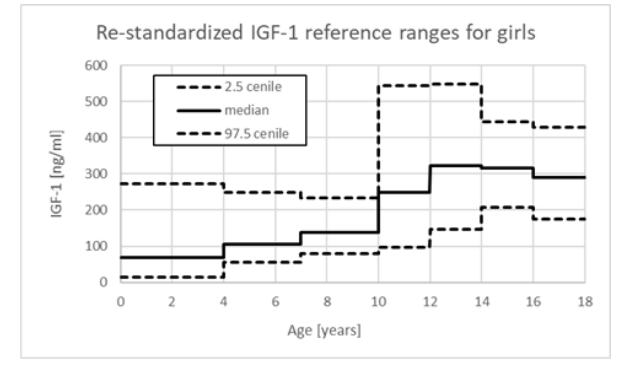

(b)

Figure 1. Centile charts based on Pediatric reference ranges for re-standardized IGF-1 assays provided for IMMULITE 2000 Immunoassay System [59]. (a) for boys; (b) for girls.

In fact, there is no lower limit of IGF-1 in age group 0-3 years, as it is defined as $<15$ $\mathrm{ng} / \mathrm{ml}$ that makes impossible using this assay for confirming IGFD in the youngest children. For boys the median value for age group 0 to 3 years $(44 \mathrm{ng} / \mathrm{ml})$ is even lower than 2.5 centile for age group 4 to 6 years $(47 \mathrm{ng} / \mathrm{ml})$, while the median for age group 12 to 13 years $(305 \mathrm{ng} / \mathrm{ml}$ ) is only slightly below the 97.5 centile for age group 10 to 11 years (315 $\mathrm{ng} / \mathrm{ml}$ ). Quite surprisingly, for girls, the value of 97.5 centile is higher in age group 0 to 3 years than in subsequent age groups up to 10 years, while the values of median and 2.5 centile in the same age groups increase with age; even more surprisingly, the median value for age group 10 to 11 years $(248 \mathrm{ng} / \mathrm{ml})$ is even higher than 97.5 centile for age group 7 to 9 years $(233 \mathrm{ng} / \mathrm{ml})$. Unfortunately, the clinicians usually interpret a single measurement (or sometimes serial measurements in the same patients) using the reference range provided by the laboratory for a given result and they must not be aware of how the reference ranges change for different age groups.

\section{Problems related to the duration of rhGH therapy in children with idiopathic GHD}

There is no doubt that rhGH therapy in a child diagnosed with GHD should be started as soon as possible. The main goals of treating short children with GHD are to improve their growth rate and to achieve normal adult height, and - in the case of severe GHD - to correct metabolic disorders. Response to rhGH therapy should be carefully monitored, especially in children diagnosed with moderate GHD despite normal IGF-1 concentration and normal MR of hypothalamic-pituitary region [12]. This enables to identify non-responders who might be misdiagnosed, e.g. due to falsely positive results of all $\mathrm{GH}$ stimulation tests performed in them. In the majority of patients treated with rhGH due to idiopathic GHD, secretion of GH appears normal after discontinuation of growth promoting treatment however, it is unclear when exactly would GH secretion be normalized. Therefore, the optimal time for retesting still remains a matter of discussion. For the patients who completed linear growth, the diagnostic criteria of adult GHD should be applied during retesting after the growth promoting therapy withdrawal in order to identify the patients with persistent severe GHD who may be candidates for even lifelong rhGH substitution.

\subsection{Early identification of non-responders}

The most important parameter in monitoring the effectiveness of rhGH therapy in children with GHD is growth response to treatment, assessed on the basis of the increase in height and in growth rate. The authors of the Consensus of 2000 [12] recommended starting rhGH therapy at the youngest possible age, before the onset of puberty. It has been considered necessary to document pre-treatment growth rate of the patients as a benchmark for assessing its improvement during the therapy. The need for careful 
documentation of height velocity was stressed by Rosenfeld et al. [11], who also suggested that normal height velocity in an untreated child spoke strongly against the diagnosis of GHD. The patients who do not respond to treatment should be reevaluated very carefully in order to ether modification the therapy (e.g. by increasing rhGH dose or just improving patient's compliance) or its withdrawal if the diagnosis of GHD is excluded. Such management allows to avoid long-term but non-effective treatment, which is also inconvenient, expensive and burdened with the possibility of side effects.

First issue to resolve is a definition of poor-responder, as there are many suggested criteria, leading to classifying different proportion of children as poor responders [60]. Second problem is establishing the rules of dealing with such patients. Bang et al. [61] discussed the strategy for prevention of poor growth response to rhGH therapy, underlying age-related dependency of responses and the difficulties in assessment of pubertal children. The authors indicated that both height velocity and increase in height SDS were considered as endpoints in prediction models, while first-year response to treatment was a standard endpoint in clinical trials. The problems with identifying poor responders, based on first-year response to rhGH administration, have recently been widely discussed by Straetemans et al. [62,63], who have stated that using different previously proposed criteria led to classifying comparable percentages of patients as poor responders, however, it turned out that different criteria were met by different patients. Unfortunately, the studies have not provided sufficient evidence on the advantage of any of the proposed criteria and - in general -have led to the conclusion that all the criteria based on first-year growth response "perform poorly as predictors of poor final height outcome" [62]. Unfortunately, extending the observation of growth response up to 2 years have not improved the prediction of poor adult height outcome after rhGH therapy [64].

The need to develop prediction models of expected growth response to treatment, enabling the estimation of the anticipated effects of rhGH therapy, was stressed at the end of the 20th century (Hindmarsh and Cole, 2000). Such models allow to determine the potential effectiveness of treatment and to make the expectations of patients and their families more realistic. They can also be useful for early identification of non-responders. Introducing the use of prediction models into clinical practice should contribute to the personalized approach to rhGH therapy [65].

Mathematical models have been applied in prediction of GH therapy effectiveness in children since the end of 1990s. An overview of the prediction models developed so far has been presented by Smyczyńska U. et al. [66]. Unfortunately, most of these models had only a few-years prediction horizon, while adult height was a predicted variable in only two of them, provided by Carel et al. [67] and de Ridder et al. [68]. Ranke et al. developed multiple linear regression models of 1-4 years response to treatment [69] and of total pubertal growth [70]. Our contribution to the creation of prediction models has been the use of neural networks for this purpose [71]. Neural networks are classified as techniques of artificial intelligence, being - in fact - advanced computational statistical methods (also known as machine learning). Neural models do not require assuming any particular character of dependencies between explained variable (output) and explanatory ones (inputs), while such assumptions are necessary for linear models. A model of firstyear response and a model of final height were created. First one was based on pre-treatment auxological and hormonal data, in the second one the inputs were the same variables and real first-year response to treatment. Conversely to the majority of previously published regression models created for children starting rhGH therapy before puberty, neural models included both prepubertal and pubertal children. Nevertheless, they have been characterized by comparable accuracy and prediction error. The problem with all prediction models is the lack of tools that would allow them to be easily used in clinical practice, for example in the form of user-friendly "calculators".

Unfortunately, management of poor-responders have not been included in recent Guidelines [1] and it still remains a matter of discussion [17,62,63]. 


\subsection{Optimal time for rhGH therapy withdrawal and retsting of GH secretion}

According to the guidelines provided by Consensus Workshop on adult GHD at Port Stephens in 1997 [72], retesting of GH and IGF-1 secretion after the attainment of final height should be undertaken by pediatric endocrinologists. Severe GHD in adults was defined in that document as GH peak in response to hypoglycemia below $3.0 \mu \mathrm{g} / \mathrm{l}$ (or decreased GH peak in alternative tests with appropriate cut-offs). Re-initiation of rhGH therapy should be considered in the patients fulfilling adult criteria of GHD and arranged in collaboration between pediatric and adult endocrinologists.

Grimberg et al. [1] have strongly recommended that rhGH therapy in pediatric doses should be withdrawn after slowing down the growth rate below 2.0-2.5 cm/year, while earlier discontinuation of treatment requires individual decisions. The moment of rhGH therapy cessation should be attainment of near-adult (near-final) height, characterized by definitely slowing down growth rate and appropriately advanced bone age (14-15 years for girls and 16-17 years for boys). Another strong recommendation has concerned the need for reassessment of GH secretion after completion of growth promotion. Although measurement of IGF-1 concentration as an initial test in reevaluation of somatotropic axis has only been a conditional recommendation, the performance of $\mathrm{GH}$ stimulation tests in the case of low IGF-1 has gained the status of a strong recommendation in next paragraph of the same document [1], which seems somewhat inconsistent.

Otherwise, over the years, reports have been published indicating that normalization of GH secretion may occur in adolescence, much earlier than at reaching near-final height.

The phenomenon of decreased GH response to pharmacological stimulation in prepubertal children with decreased growth rate and normalization of GH secretion after the onset of puberty was described more than 40 years ago by Gourmelen et al. [18]. The authors speculated that their observation would suggest a transient and functional GHD before puberty and influence of sex hormones on GH secretion. This justified the need to reassess GH secretion in patients diagnosed with GHD as children. Similarly, Zucchini et al. [73] reported normal results of GH stimulation tests after the onset of puberty in the majority of children, diagnosed with isolated GHD in prepubertal period. Moreover, the authors documented that there was no significant difference in final height between the patients, who suspended rhGH therapy due to normal GH secretion at retesting and those with confirmed GHD, who were treated up to completion of linear growth.

More recently, Penta et al. [74] have confirmed permanent GHD in transition period in only $16 \%$ of the patients diagnosed with isolated, idiopathic GHD in childhood and have suggested that the time of retesting should be anticipated in order to avoid overtreatment. Cavarzere et al. [2] have performed retesting of GH secretion in mid-puberty in a group of children diagnosed previously with idiopathic GHD and discontinued rhGH therapy in over half of them with normal GH peaks at retesting, while restarted in those with confirmed GHD. Interestingly, in this study, the only predictor of persistent and transient GHD has been IGF-1 concentration (and IGF-1 SDS) after 1 year of rhGH therapy. Both groups of patients have been observed up to the achievement of near-final height and no difference between them has been found in both height increase and final height. Thus the authors have concluded that GH secretion should be retested in midpuberty. In line with these studies remain the results presented by Krukowska-Andrzejczyk et al. [75], who have compared height SDS increase obtained during rhGH therapy in a group of patients diagnosed in childhood with partial GHD (i.e. with GH peaks in stimulation tests between 5.0 and $10.0 \mu \mathrm{g} / \mathrm{l}$ ), which turned out to be transient in retesting, with that occurring spontaneously in a group of untreated children with ISS. Mean final height was normal in both groups and there was no significant difference in the observed height gain between them. The authors have also stated that there has been a necessity to determine other criteria of qualifying children to rhGH therapy than the arbitrarily established cut-off value for GH peak in stimulation test.

Poor reproducibility of the results of GH stimulation tests has been reconsidered as a possible cause of early normalization of GH secretion that might occur during mid- 
puberty [2] or even earlier [33,76]. Nevertheless, there is still no consensus regarding retesting of GH secretion earlier than at the attainment of near-final height.

\section{Concluding remarks}

According to Rosenfeld et al. [11], the question who should be tested for GHD was even more important than the question how to test for GHD. This constatation seems to be also valid nowadays, after 25 years. More recently, Ranke et al. [77] have summarized 50 years of GH use in children with non-acquired GHD, treated in a single center and have observed the tendency to more stringent diagnostic criteria for GHD in recent years, including assessment of pre-treatment growth rate, sex steroid priming and lowering cutoffs for GH stimulation tests, restricting diagnoses of GHD to more severe cases. Felício et al. [78] have proposed diagnosis of idiopathic GHD based on clinical, auxological and radiological assessment, confirmed by GH peak in stimulation tests below $7.0 \mu \mathrm{g} / \mathrm{l}$ and IGF-1 SDS below -2.0. On the other hand, the proved effectiveness of rhGH therapy in children diagnosed with ISS has been a background to approve this indication for treatment [79], however not in all countries.

It seems that finding solutions to the problems discussed in the present study may contribute to the optimization of diagnostics and therapy of children with short stature. Many of these issues have also been addressed in the review published by Henry in 2020 [80]. Moreover, an important part of that paper has been devoted to ethical implications of diagnosing GHD in children. Trying to answer, why the cut-off value of GH peak in stimulation tests on the level of $10.0 \mu \mathrm{g} / \mathrm{l}$ has not been changed despite the evidence that it should be lower, the author has stated that it might be caused by difficulties in establishing normal values for GH secretion at population level, but also by issues far from evidence-based medicine, like a fear of reduction of revenue from therapy. He has also stated that, as current rules of GH testing have carried a considerable risk of false positive results, stimulation tests should be performed only in the patients with a high clinical likelihood of GHD. This remark is in line with the previously discussed proposal of Wit et al. [5]. Also Kamoun et al. [81] have summed up the limitations of GH stimulation tests and have stressed the need for developing new diagnostic modalities in future, while now improving the clinical application of GH stimulation tests by taking into account all factors that may influence their results. Very recently, Rodari at al. [82] have confirmed the rationale for decreasing the cut-off value of $\mathrm{GH}$ peak in stimulation tests, together with highlighting the need of reconsidering NSD as a rhGH-treatable disease related to hypothalamic derangement with the clinical presentation similar to that of isolated GHD.

Although bioethical and economic issues have not been the subject of the present study, nevertheless they are also relevant to the proper management of patients. In this context, it is worth citing once more the recent paper of Henry [80], who has presented the thesis that rhGH use in other conditions than "true" GHD may be considered as "cosmetic endocrinology". This opinion may seem somewhat surprising, but it nevertheless requires some reflection. However, taking into account the limitations of available diagnostic tests, it may be difficult to qualify to rhGH therapy all the patients who will benefit from this and only such ones. It seems proven that the use of rhGH for growth promotion may be effective and justified not only in children with decreased GH peak in stimulation tests. On the other hand, the therapy duration in children diagnosed with isolated idiopathic GHD could be shortened, at least in some cases, with no harm to patients.

Funding: This research received no external funding.

Acknowledgments: I would like to thank the co-authors of cited papers from Medical University of Lodz, Poland, for many years of inspiring cooperation: Prof. Andrzej Lewiński - Head of Department of Endocrinology and Metabolic Diseases, Prof. Renata Stawerska - Head of Department of Pediatric Endocrinology, Prof. Maciej Hilczer - former Head of Department of Pediatric Endocrinology and Urszula Smyczyńska, Msc, PhD from Department of Biostatistics and Translational Medicine. 
Conflicts of Interest: The author declare no conflict of interest

\section{References}

1. Grimberg, A.; DiVall, S.A.; Polychronakos, C.; Allen, D.B.; Cohen, L.E.; Quintos, J.B.; Rossi, W.C.; Feudtner, C.; Murad, M.H. Guidelines for Growth Hormone and Insulin-Like Growth Factor-I Treatment in Children and Adolescents: Growth Hormone Deficiency, Idiopathic Short Stature, and Primary Insulin-Like Growth Factor-I Deficiency. Horm. Res. Paediatr. 2016, 86, 361397.

2. Cavarzere, P.; Gaudino, R.; Sandri, M.; Ramaroli, D.A.; Pietrobelli, A.; Zaffanello, M.; Guzzo, A.; Salvagno, G.L.; Piacentini, G.; Antoniazzi, F. Growth hormone retesting during puberty: a cohort study. Eur. J. Endocrinol. 2020, 182, 559-567. DOI: 10.1530/eje19-0646.

3. Wit, J.-M.; Ranke, M.B.; Kelnar, C.J.H. The ESPE classification of paediatric endocrine diagnoses. Horm. Res. 2007, 68, 1-120.

4. Savage, M.O.; Burren, C.P.; Rosenfeld, R.G. The continuum of growth hormone-IGF-I axis defects causing short stature: diagnostic and therapeutic challenges. Clin. Endocrinol. (Oxf). 2010, 72, 721-728. DOI: 10.1111/j.1365-2265.2009.03775.x.

5. Wit, J.M.; Bidlingmaier, M.; Bruin, C. De A Proposal for the Interpretation of Serum IGF-I Concentration as Part of Laboratory Screening in Children with Growth Failure. J. Clin. Res. Pediatr. Endocrinol. 2020, 12, 130-139.

6. Spiliotis, B.E.; Alexandrides, T.K.; Karystianos, C.; Vassilakos, P.; Zadik, Z.; Nikolakopoulou, N.M.; Nikiforidis, G.; Beratis, N.G. The insulin-like growth factor-I (IGF-I) generation test as an indicator of growth hormone status. Hormones 2009, 8, 117-128.

7. Buckway CK, Rosenfeld, R.G. The IGF-I Generation Test Revisited: A Marker of GH Sensitivity. J. Clin. Endocrinol. Metab. 2001, 86, 5176-5183.

8. Cotterill, A.M.; Camacho-Hübner, C.; Duquesnoy, P.; Savage, M.O. Changes in serum IGF-I and IGFBP-3 concentrations during the IGF-I generation test performed prospectively in children with short stature. Clin. Endocrinol. (Oxf). 1998, 48, 719-724. DOI: 10.1046/j.1365-2265.1998.00407.x.

9. Coutant, R.; Dorr, H.-G.; Gleeson, H.; Argente, J. Diagnosis of endocrine disease: limitations of the IGF1 generation test in children with short stature. Eur. J. Endocrinol. 2012, 166, 351-357. DOI: doi:10.1530/EJE-11-0618.

10. Storr, H.L.; Chatterjee, S.; Metherell, L.A.; Foley, C.; Rosenfeld, R.G.; Backeljauw, P.F.; Dauber, A.; Savage, M.O.; Hwa, V. Nonclassical GH Insensitivity: Characterization of Mild Abnormalities of GH Action. Endocr. Rev. 2019, 40, 476-505. DOI: 10.1210/er.2018-00146.

11. Rosenfeld, R.G.; Albertsson-Wikland, K.; Cassorla, F.; Frasier, S.D.; Hasegawa, Y.; Hintz, R.L.; Lafranchi, S.; Lippe, B.; Loriaux, L.; Melmed, S.; et al. Diagnostic Controversy - the Diagnosis of Childhood Growth-Hormone Deficiency Revisited. J. Clin. Endocrinol. Metab. 1995, 80, 1532-1540. DOI: 10.1210/jc.80.5.1532.

12. Growth Hormone Research Society Consensus guidelines for the diagnosis and treatment of growth hormone (GH) deficiency in childhood and adolescence: summary statement of the GH Research Society. GH Research Society. J. Clin. Endocrinol. Metab. 2000, 85, 3990-3. DOI: 10.1210/jcem.85.11.6984.

13. Bright, G.M.; Julius, J.R.; Lima, J.; Blethen, S.L. Growth hormone stimulation test results as predictors of recombinant human growth hormone treatment outcomes: preliminary analysis of the national cooperative growth study database. Pediatrics 1999, 104, 1028-1031.

14. Smyczyńska, J.; Lewiński, A.; Hilczer, M.; Stawerska, R.; Karasek, M. Partial growth hormone deficiency (GHD) in children has more similarities to idiopathic short stature than to severe GHD. Endokrynol. Pol. 2007, 58, 182-187

15. Webb, E.A.; Dattani, M.T. Diagnosis of growth hormone deficiency. Endocr. Dev. 2010, 18, 55-66. DOI: 10.1159/000316127.

16. Wagner, I. V.; Paetzold, C.; Gausche, R.; Vogel, M.; Koerner, A.; Thiery, J.; Arsene, C.G.; Henrion, A.; Guettler, B.; Keller, E.; et al. Clinical evidence-based cutoff limits for GH stimulation tests in children with a backup of results with reference to mass spectrometry. Eur. J. Endocrinol. 2014, 171, 389-397. DOI: 10.1530/EJE-14-0165.

17. Murray, P.G.; Dattani, M.T.; Clayton, P.E. Controversies in the diagnosis and management of growth hormone deficiency in childhood and adolescence. Arch. Dis. Child. 2016, 101, 96-100. DOI: 10.1159/000452150.

18. Gourmelen, M.; Pham-Huu-Tsrung, M.T.; Girard, F. Transient partial hGH deficiency in prepubertal children with delay of growth. Pediatr. Res. 1979, 13, 221-224. DOI: 10.1203/00006450-197904000-00002.

19. Mauras, N.; Blizzard, R.M.; Link, K.; Johnson, M.L.; Rogol, A.D.; Veldhuis, J.D. Augmentation of growth hormone secretion during puberty: evidence for a pulse amplitude-modulated phenomenon. J. Clin. Endocrinol. Metab. 1987, 64, 596-601. DOI: 10.1210/jcem-64-3-596.

20. Marin, G.; Domené, H.M.; Barnes, K.M.; Blackwell, B.J.; Cassorla, F.G.; Cutler, G.B.J. The effects of estrogen priming and puberty on the growth hormone response to standardized treadmill exercise and arginine-insulin in normal girls and boys. J. Clin. Endocrinol. Metab. 1994, 79, 537-541. DOI: 10.1210/jcem.79.2.8045974.

21. Gonc, E.N.; Kandemir, N.; Ozon, A.; Alikasifoglu, A. Final heights of boys with normal growth hormone responses to provocative tests following priming. J. Pediatr. Endocrinol. Metab. 2008, 21, 963-971. DOI: 10.1515/jpem.2008.21.10.963.

22. Radetti, G.; Elsedfy, H.H.; Khalaf, R.; Meazza, C.; Pagani, S.; El Kholy, M.; Albertini, R.; De Stefano, A.M.; Navarra, A.; De Silvestri, A.; et al. Pegvisomant-primed growth hormone (GH) stimulation test is useful in identifying true GH deficient children. Hormones 2017, 16, 291-296. DOI: 10.14310/horm.2002.1748.

23. Stanley, T.L.; Levitsky, L.L.; Grinspoon, S.K.; Misra, M. Effect of body mass index on peak growth hormone response to provocative testing in children with short stature. J. Clin. Endocrinol. Metab. 2009, 94, 4875-4881. DOI: 10.1210/jc.2009-1369. 
24. Barrett, J.; Maranda, L.; Nwosu, B.U. The relationship between subnormal peak-stimulated growth hormone levels and auxological characteristics in obese children. Front. Endocrinol. (Lausanne). 2014, 5, 5-10. DOI: 10.3389/fendo.2014.00035.

25. Yang, A.; Cho, S.Y.; Kwak, M.J.; Kim, S.J.; Park, S.W.; Jin, D.K.; Lee, J.E. Impact of BMI on peak growth hormone responses to provocative tests and therapeutic outcome in children with growth hormone deficiency. Sci. Rep. 2019, 9, 1-10. DOI: 10.1038/s41598-019-52644-1.

26. Lennartsson, O.; Nilsson, O.; Lodefalk, M. Discordance Between Stimulated and Spontaneous Growth Hormone Levels in Short Children Is Dependent on Cut-Off Level and Partly Explained by Refractoriness. Front. Endocrinol. (Lausanne). 2020, 11, 1-9. DOI: 10.3389/fendo.2020.584906.

27. Abawi, O.; Augustijn, D.; Hoeks, S.E.; de Rijke, Y.B.; van den Akker, E.L.T. Impact of body mass index on growth hormone stimulation tests in children and adolescents: a systematic review and meta-analysis. Crit. Rev. Clin. Lab. Sci. 2021, 58, 576-595. DOI: 10.1080/10408363.2021.1956423.

28. Kelnar, C.J.H. The evidence base for growth hormone effectiveness in children. Endocr. Dev. 2010, 18, 23-39. DOI: doi:10.1159/000316125.

29. Cole, T.J.; Hindmarsh, P.C.; Dunger, D.B. Growth hormone $(\mathrm{GH})$ provocation tests and the response to GH treatment in GH deficiency. Arch. Dis. Child. 2004, 89, 1024-1027. DOI: 10.1136/adc.2003.043406.

30. Zadik, Z.; Chalew, S.A.; Gilula, Z.; Kowarski, A.A. Reproducibility of growth hormone testing procedures: a comparison between 24-hour integrated concentration and pharmacological stimulation. J. Clin. Endocrinol. Metab. 1990, 71, 1127-1130. DOI: 10.1210/jcem-71-5-1127.

31. Hintz, R.L. Growth Hormone Neurosecretory Dysfunction as a Clinical Entity. Clin. Pediatr. Endocrinol. 1995, 4, 9-19. DOI: 10.1297/cpe.4.Supple6_9.

32. Hilczer, M.; Smyczynska, J.; Lewinski, A. Limitations of clinical utility of growth hormone stimulating tests in diagnosing children with short stature. Endocr. Regul. 2006, 40, 69-75.

33. Loche, S.; Bizzarri, C.; Maghnie, M.; Faedda, A.; Tzialla, C.; Autelli, M.; Casini, M.R.; Cappa, M. Results of early reevaluation of growth hormone secretion in short children with apparent growth hormone deficiency. J. Pediatr. 2002, 140, 445-449. DOI: 10.1067/mpd.2002.122729.

34. Hilczer, M.; Smyczynska, J.; Stawerska, R.; Lewinski, A. Stability of IGF-I concentration despite divergent results of repeated GH stimulating tests indicates poor reproducibility of test results. Endocr. Regul. 2006, 40, 37-45.

35. Wit, J.M.; Joustra, S.D.; Losekoot, M.; Van Duyvenvoorde, H.A.; De Bruin, C. Differential diagnosis of the short IGF-I-deficient child with apparently normal growth hormone secretion. Horm. Res. Paediatr. 2021, 94, 81-104. DOI: 10.1159/000516407.

36. Obara-Moszynska, M.; Kedzia, A.; Korman, E.; Niedziela, M. Usefulness of growth hormone (GH) stimulation tests and IGF-I concentration measurement in GH deficiency diagnosis. J. Pediatr. Endocrinol. Metab. 2008, 21, 569-579.

37. Smyczyńska, J.; Stawerska, R.; Lewiński, A.; Hilczer, M. Limited usefulness of the test of spontaneous growth hormone (GH) nocturnal secretion as a screening procedure in diagnosing GH deficiency in children with short stature. Ann. Agric. Environ. Med. 2014, 21, 893-897. DOI: 10.5604/12321966.1129954.

38. Rose, S.R.; Ross, J.L.; Uriarte, M.; Barnes, K.M.; Cassorla, F.G.; Cutler, G.B.J. The advantage of measuring stimulated as compared with spontaneous growth hormone levels in the diagnosis of growth hormone deficiency. N. Engl. J. Med. 1988, 319, 201-207. DOI: 10.1056/NEJM198807283190403.

39. Spiliotis, B.E.; August, G.P.; Hung, W.; Sonis, W.; Mendelson, W.; Bercu, B.B. Growth hormone neurosecretory dysfunction. A treatable cause of short stature. JAMA 1984, 251, 2223-2230.

40. Radetti, G.; Buzi, F.; Cassar, W.; Paganini, C.; Stacul, E.; Maghnie, M. Growth hormone secretory pattern and response to treatment in children with short stature followed to adult height. Clin. Endocrinol. (Oxf). 2003, 59, 27-33. DOI: 10.1046/j.13652265.2003.01773.x.

41. Rogol, A.D.; Blethen, S.L.; Sy, J.P.; Veldhuis, J.D. Do growth hormone (GH) serial sampling, insulin-like growth factor-I (IGF-I) or auxological measurements have an advantage over GH stimulation testing in predicting the linear growth response to GH therapy? Clin. Endocrinol. (Oxf). 2003, 58, 229-37. DOI: 10.1046/j.1365-2265.2003.01701.x.

42. Wit, J.M.; Deeb, A.; Bin-Abbas, B.; Al Mutair, A.; Koledova, E.; Savage, M.O. Achieving optimal short- and long-term responses to paediatric growth hormone therapy. J. Clin. Res. Pediatr. Endocrinol. 2019, 11, 329-340. DOI: 10.4274/jcrpe.galenos.2019.2019.0088.

43. Binder, G.; Hähnel, J.; Weber, K.; Schweizer, R. Adult height after treatment of neurosecretory dysfunction and comparison to idiopathic GHD. Clin. Endocrinol. (Oxf). 2021, Oct 13. DOI: 10.1111/cen.14608.

44. Blum, W.F.; Albertsson-Wikland, K.; Rosberg, S.; Ranke, M.B. Serum levels of insulin-like growth factor I (IGF-I) and IGF binding protein 3 reflect spontaneous growth hormone secretion. J. Clin. Endocrinol. Metab. 1993, 76, 1610-1616. DOI: 10.1210/jcem.76.6.7684744.

45. Ho, K.K.Y. Consensus guidelines for the diagnosis and treatment of adults with GH deficiency II: A statement of the GH Research Society in association with the European Society for Pediatric Endocrinology, Lawson Wilkins Society, European Society of Endocrinology. Eur. J. Endocrinol. 2007, 157, 695-700. DOI: 10.1530/EJE-07-0631.

46. Ibba, A.; Corrias, F.; Guzzetti, C.; Casula, L.; Salerno, M.; Di Iorgi, N.; Tornese, G.; Patti, G.; Radetti, G.; Maghnie, M.; et al. Igf1 for the diagnosis of growth hormone deficiency in children and adolescents: A reappraisal. Endocr. Connect. 2020, 9, $1095-1102$. DOI: 10.1530/EC-20-0347. 
47. Iwayama, H.; Kitagawa, S.; Sada, J.; Miyamoto, R.; Hayakawa, T.; Kuroyanagi, Y.; Muto, T.; Kurahashi, H.; Ohashi, W.; Takagi, J.; et al. Insulin-like growth factor-1 level is a poor diagnostic indicator of growth hormone deficiency. Sci. Rep. 2021, 11, 1-6. DOI: $10.1038 /$ s41598-021-95632-0.

48. Smyczyńska, J.; Lewiński, A.; Stawerska, R.; Hilczer, M.; Karasek, M. Assessment of insulin-like growth factor-I serum concentration as a screening procedure in diagnosing children with short stature. Neuroendocrinol. Lett. 2007, $28,274-278$.

49. Meazza, C.; Elsedfy, H.H.; Khalaf, R.I.; Lupi, F.; Pagani, S.; Kholy, M. El; Tinelli, C.; Radetti, G.; Bozzola, M. Serum $\alpha$-klotho levels are not informative for the evaluation of growth hormone secretion in short children. J. Pediatr. Endocrinol. Metab. 2017, 30, 1055-1059. DOI: 10.1515/jpem-2016-0464.

50. Savage, M.O.; Blum, W.F.; Ranke, M.B.; Postel-Vinay, M.C.; Cotterill, A.M.; Hall, K.; Chatelain, P.G.; Preece, M.A.; Rosenfeld, R.G. Clinical features and endocrine status in patients with growth hormone insensitivity (Laron syndrome). J. Clin. Endocrinol. Metab. 1993, 77, 1465-1471. DOI: 10.1210/jcem.77.6.7505286.

51. Rudman, D.; Kutner, M.H.; Blackston, R.D.; Cushman, R.A.; Bain, R.P.; Patterson, J.H. Children with normal-variant short stature: treatment with human growth hormone for six months. N. Engl. J. Med. 1981, 305, 123-131. DOI: 10.1056/NEJM198107163050302.

52. Jorge, A.A.; Souza, S.C.; Arnhold, I.J.; Mendonca, B.B. Poor reproducibility of IGF-I and IGF binding protein-3 generation test in children with short stature and normal coding region of the GH receptor gene. J. Clin. Endocrinol. Metab. 2002, 87, 469-472. DOI: $10.1210 /$ jcem.87.2.8191.

53. Smyczyńska, J.; Smyczyńska, U.; Hilczer, M.; Stawerska, R.; Lewiński, A. Significance of direct confirmation of growth hormone insensitivity for the diagnosis of primary IGF-I deficiency. J. Clin. Med. 2020, 9. DOI: 10.3390/jcm9010240.

54. Smyczyńska, J.; Hilczer, M.; Stawerska, R.; Lewiński, A. Significant increase of IGF-I concentration and of IGF-I/IGFBP-3 molar ratio in generation test predicts the good response to growth hormone $(\mathrm{GH})$ therapy in children with short stature and normal results of GH stimulating tests. Neuroendocrinol. Lett. 2013, 34, 222-228.

55. Hilczer, M.; Smyczyńska, J.; Lewiński, A. Monitoring and optimising of growth hormone (GH) therapy in GH-deficient children - the role of assessment of insulin-like growth factor-I (IGF-I) secretion and IGF-I/IGF binding protein-3 molar ratio. Med. Sci. Technol. 2006, 47, 219-223.

56. Gaddas, M.; Périn, L.; Le Bouc, Y. Evaluation of IGF1/IGFBP3 molar ratio as an effective tool for assessing the safety of growth hormone therapy in small-for-gestational-age, growth hormone-deficient and prader-willi children. JCRPE J. Clin. Res. Pediatr. Endocrinol. 2019, 11, 253-261. DOI: 10.4274/jcrpe.galenos.2019.2018.0277.

57. Elmlinger, M.W.; Kühnel, W.; Weber, M.M.; Ranke, M.B. Reference ranges for two automated chemiluminescent assays for serum insulin-like growth factor I (IGF-I) and IGF-binding protein 3 (IGFBP-3). Clin. Chem. Lab. Med. 2004, 42, 654-664. DOI: 10.1515/CCLM.2004.112.

58. Blum, W.F.; Schweizer, R. Insulin-like growth factors and their binding proteins. In Diagnostics of Endocrine Function in Children and Adolescents; Ranke, M.B., Ed.; Karger, Basel, 2003; pp. 166-169.

59. Siemens Healthcare Diagnostics Inc. Introducing the Restandardized Insulin-Like Growth Factor-I (IGF-I) Assay. Cust. Bull. 2016, 5 .

60. Bang, P.; Bjerknes, R.; Dahlgren, J.; Dunkel, L.; Gustafsson, J.; Juul, A.; Kriström, B.; Tapanainen, P.; Åberg, V. A comparison of different definitions of growth response in short prepubertal children treated with growth hormone. Horm. Res. Paediatr. 2011, 75, 335-345. DOI: 10.1159/000322878.

61. Bang, P.; Ahmed, S.F.; Argente, J.; Backeljauw, P.; Bettendorf, M.; Bona, G.; Coutant, R.; Rosenfeld, R.G.; Walenkamp, M.-J.; Savage, M.O. Identification and management of poor response to growth-promoting therapy in children with short stature. Clin. Endocrinol. (Oxf). 2012, 77, 169-181. DOI: 10.1111/j.1365-2265.2012.04420.x.

62. Straetemans, S.; De Schepper, J.; Thomas, M.; Tenoutasse, S.; Beauloye, V.; Rooman, R. Criteria for First-Year Growth Response to Growth Hormone Treatment in Prepubertal Children With Growth Hormone Deficiency: Do They Predict Poor Adult Height Outcome? Front. Endocrinol. (Lausanne). 2019, 10. DOI: 10.3389/fendo.2019.00792. DOI: 10.3389/fendo.2019.00792.

63. Straetemans, S.; Thomas, M.; Craen, M.; Rooman, R.; De Schepper, J. Poor growth response during the first year of growth hormone treatment in short prepubertal children with growth hormone deficiency and born small for gestational age: a comparison of different criteria. Int. J. Pediatr. Endocrinol. 2018, 2018, 1-10. DOI: 10.1186/s13633-018-0064-3.

64. Straetemans, S.; Rooman, R.; De Schepper, J. Is a Two-Year Growth Response to Growth Hormone Treatment a Better Predictor of Poor Adult Height Outcome Than a First-Year Growth Response in Prepubertal Children With Growth Hormone Deficiency? Front. Endocrinol. (Lausanne). 2021, 12, 1-9. DOI: doi:10.3389/fendo.2021.678094.

65. Wit, J.M.; Ranke, M.B.; Albertsson-Wikland, K.; Carrascosa, A.; Rosenfeld, R.G.; Van Buuren, S.; Kristrom, B.; Schoenau, E.; Audi, L.; Hokken-Koelega, A.C.S.; et al. Personalized Approach to Growth Hormone Treatment: Clinical Use of Growth Prediction Models. Horm. Res. Paediatr. 2013, 79, 257-270. DOI: 10.1159/000351025.

66. Smyczyńska, U.; Smyczyńska, J.; Tadeusiewicz, R. Neural modelling of growth hormone therapy for the prediction of therapy results. Bio-Algorithms and Med-Systems 2015, 11, 33-45. DOI: 10.1515/bams-2014-0021.

67. Carel, J.C.; Ecosse, E.; Nicolino, M.; Tauber, M.; Leger, J.; Cabrol, S.; Bastie-Sigeac, I.; Chaussain, J.L.; Coste, J. Adult height after long term treatment with recombinant growth hormone for idiopathic isolated growth hormone deficiency: observational follow up study of the French population based registry. BMJ 2002, 325, 70. DOI: 10.1136/bmj.325.7355.70.

68. de Ridder, M.A.J.; Stijnen, T.; Hokken-Koelega, A.C.S. Prediction of adult height in growth-hormone-treated children with growth hormone deficiency. J. Clin. Endocrinol. Metab. 2007, 92, 925-931. DOI: 10.1210/jc.2006-1259. 
69. Ranke, M.B.; Lindberg, A.; Chatelain, P.; Wilton, P.; Cutfield, W.; Albertsson-Wikland, K.; Price, D.A. Derivation and Validation of a Mathematical Model for Predicting the Response to Exogenous Recombinant Human Growth Hormone (GH) in Prepubertal Children with Idiopathic GH Deficiency. J. Clin. Endocrinol. Metab. 1999, 84, 1174-1183. DOI: 10.1210/jcem.84.4.5634.

70. Ranke, M.B.; Lindberg, A.; Martin, D.D.; Bakker, B.; Wilton, P.; Albertsson-Wikland, K.; Cowell, C.T.; Price, D.A.; Reiter, E.O.; Kabi Intl Growth Study Pfizer, I. The mathematical model for total pubertal growth in idiopathic growth hormone (GH) deficiency suggests a moderate role of GH dose. J. Clin. Endocrinol. Metab. 2003, 88, 4748-4753. DOI: 10.1210/jc.2003-030600.

71. Smyczyńska, U.; Smyczyńska, J.; Hilczer, M.; Stawerska, R.; Tadeusiewicz, R.; Lewiński, A. Pre-treatment growth and IGF-I deficiency as main predictors of response to growth hormone therapy in neural models. Endocr. Connect. 2018, 7. DOI: 10.1530/EC-17-0277.

72. Attanasio, A.; Attie, K.; Baxter, R.; Bengtsson, B.-A.; Black, A.; Blethen, S.; Carlsson, L.; Casaneuva, F.; Chipman, J.; Christiansen, J.S.; et al. Consensus guidelines for the diagnosis and treatment of adults with growth hormone deficiency: Summary statement of the growth hormone research society workshop on adult growth hormone deficiency. J. Clin. Endocrinol. Metab. 1998, 83, 379381. DOI: $10.1210 /$ jc.83.2.379.

73. Zucchini, S.; Pirazzoli, P.; Baronio, F.; Gennari, M.; Bal, M.O.; Balsamo, A.; Gualandi, S.; Cicognani, A. Effect on adult height of pubertal growth hormone retesting and withdrawal of therapy in patients with previously diagnosed growth hormone deficiency. J. Clin. Endocrinol. Metab. 2006, 91, 4271-4276. DOI: 10.1210/jc.2006-0383.

74. Penta, L.; Cofini, M.; Lucchetti, L.; Zenzeri, L.; Leonardi, A.; Lanciotti, L.; Galeazzi, D.; Verrotti, A.; Esposito, S. Growth hormone $(\mathrm{GH})$ therapy during the transition period: Should we think about early retesting in patients with idiopathic and isolated GH deficiency? Int. J. Environ. Res. Public Health 2019, 16. DOI: 10.3390/ijerph16030307.

75. Krukowska-Andrzejczyk, B.J.; Kalina, M.; Kalina-Faska, B.; Małecka-Tendera, E. Growth hormone therapy in children with partial growth hormone deficiency. Are we treating the right patients? Pediatr. Endocrinol. Diabetes Metab. 2020, 26, 65-72. DOI: 10.5114/pedm.2020.95624.

76. Hilczer, M.; Smyczyńska, J.; Stawerska, R.; Lewiński, A. Stability of IGF-I concentration despite divergent results of repeated GH stimulating tests indicates poor reproducibility of test results. Endocr. Regul. 2006, 40, 37-45.

77. Ranke, M.B.; Schweizer, R.; Binder, G. Basal characteristics and first year responses to human growth hormone (GH) vary according to diagnostic criteria in children with non-acquired GH deficiency (naGHD): observations from a single center over a period of five decades. J. Pediatr. Endocrinol. Metab. 2018, 31, 1257-1266. DOI: 10.1515/jpem-2018-0025.

78. Felício, J.S.; Janaú, L.C.; Moraes, M.A.; Zahalan, N.A.; de Souza Resende, F.; de Lemos, M.N.; de Souza Neto, N.J.K.; Farias de Franco, I.I.; Leitão, L.T.C.; Silva, L. de S. d. A.; et al. Diagnosis of Idiopathic GHD in Children Based on Response to rhGH Treatment: The Importance of GH Provocative Tests and IGF-1. Front. Endocrinol. (Lausanne). 2019, 10, 1-9. DOI: 10.3389/fendo.2019.00638.

79. Cohen, P.; Rogol, A.D.; Deal, C.L.; Saenger, P.; Reiter, E.O.; Ross, J.L.; Chernausek, S.D.; Savage, M.O.; Wit, J.M. Consensus statement on the diagnosis and treatment of children with idiopathic short stature: a summary of the Growth Hormone Research Society, the Lawson Wilkins Pediatric Endocrine Society, and the European Society for Paediatric Endocrinology Workshop. J. Clin. Endocrinol. Metab. 2008, 93, 4210-4217. DOI: 10.1210/jc.2008-0509.

80. Henry, R.K. Childhood growth hormone deficiency, a diagnosis in evolution: The intersection of growth hormone history and ethics. Growth Horm. IGF Res. 2020, 55, 101358. DOI: 10.1016/j.ghir.2020.101358.

81. Kamoun, C.; Hawkes, C.P.; Grimberg, A. Provocative growth hormone testing in children: how did we get here and where do we go now? J. Pediatr. Endocrinol. Metab. 2021, 34, 679-696. DOI: 10.1515/jpem-2021-0045.

82. Rodari, G.; Profka, E.; Giacchetti, F.; Cavenaghi, I.; Arosio, M.; Giavoli, C. Influence of biochemical diagnosis of growth hormone deficiency on replacement therapy response and retesting results at adult height. Sci. Rep. 2021, 11, 1-10. DOI: 10.1038/s41598021-93963-6. 